\title{
Basic Framework and Significance on the Economics of Port Safety
}

\author{
Zhang Shijie, Liu Yan, Zhuang Rong and Wang Xuting \\ Tianjin Research Institute of Water Transport Engineering of Ministry of Transport, Tianjin, China
}

\begin{abstract}
This article is based on drawing lessons from the basic theory of safety economics, such as the basic concepts, principles, theories, research methods, etc.; and is combined with the actual on the safety production of port enterprises. It has expounded the basic theory on the economics of port safety, such as basic connotation, subject investigated and research method; and has pointed out the basic features. The significance and value of research on the economics of port safety have been analysed in article. The basic framework on the economics of port safety has sketched in this article.
\end{abstract}

\section{Introduction}

With the continuous development of national economy and society, the guidelines, policies, and theories of safety management have being continuous innovation, and the models on port safety management have significantly changed. It is transforming from paying attention to after the accident treatment, to attaching great importance to accident prevention before accident. Port enterprises gradually establish the safety concept such as safety first, prevention first, safety development, etc.; increase safety investments; introduce the methods of risk management; and have achieved good results.

However, port enterprises generally encountered some common problems in practical work. The first, how to define and measure safety investment (cost) and to know and evaluate safety benefit (output). The second, in the case of that safety investments are limited, how to optimize the distribution the resources of human, material and financial, in order to obtain the biggest safety benefits. The third, in the premise that fulfilling the requirements for the safety regulations and standards and ensuring the due level of safety, how to reduce the safety investments or to reduce unnecessary investments. The fourth, how to scientifically evaluate the risk of the safety in production, how to reasonably determine the indexes of risk control, and how to properly handle the relationship between safety investments and safety benefits. These problems are so confused not only port enterprises, and including with the correlative government departments on port safety production, scientific research and consulting institutions.

The above problems are the basic problems of safety economics [1,2]. Over the years, according to the research on safety economics carried out less in China, and research on the economics of port safety at home and abroad is in the initial stage of starting, so the research results cannot see much.

The economics of port safety is a new subject. Because of the lack of theoretical guidance and scientific evaluation method, evaluation standard, for the research of this subject, there are some unreasonable, undesirable method of work, for safety investments, in some port enterprises.

For example, some port enterprises one-sided focus on the safety equipment and facilities investments (hardware) and ignore the safety management investments (software, including organization, personnel, education, training and so on), or on the contrary. Some port enterprises mistakenly believe that there are only investments and no benefits in safety production, or large investments and small benefits, therefore they are not willing to do investments, or reduce investments. And there are a small number of enterprises which constitute too high safety objectives that divorced from reality, causing that port aspire after zero accidents or zero risk, and blindly increase safety investments, too much to increase the economic burden of port enterprises.

With the importance of port safety has become increasingly prominent, the research of the actual effect and the economic relationship problems for port safety is especially urgent and important. From this point of view, there are very realistic basic functions that be as soon as possible to carry out the research of the economics of port safety, to research on the basic characteristics, content, research methods for the economics of port safety, and to define some basic concepts as the initial phase of research for the economics of port safety.

\section{Subject investigated}

From the angle of subject property and task, the definition for the economics of port safety can be given 
$[1,3,4]$. The economics of port safety is a science that studying, which study economy (the interests, investment, benefit) forms and conditions for port safety, through the reasonable organization, control and adjustment of port safety activities, in order to reach the biggest benefits of safety for human, technology, and environment [3]. It is thus clear that the economics of port safety is a science which is to research the relationships between the safety activities of ports with the economic activities of ports. This definition has the following meanings: the subject investigated for the economics of port safety is the economic form and condition of port safety, that is, through theoretical research and analysis, in order to reveal and clarify the form of expression and the realization condition of the port safety behalves, safety investments, and safety benefits. The objectives for the economics of port safety are to achieve optimum safety benefit [5] the three which are human, technology, and environment.

The goal for the economics of port safety is achieved through the control and adjustment of the port safety activity. Port safety activities refer to the activities carried out in order to ensure the safety for port enterprises, which is including that: setting regulation and police for port safety, safety education and management, the implementation of safety engineering and technology, etc. Safety activities require a fair amount of human resources, material resources and financial resources, these resources are called port safety investments [6,7]. It will hope to obtain the corresponding rewards when to invest. The investment return for port safety is to ensure safety, and reduce accidents and reduce the loss of accident in port transportation. This also indirectly promote the added value for port economy production. Therefore, the safety activities of port is not only a kind of "consumption activity", or "investment activities" and "benefit activities".

The economics of port safety also has itself subject investigated, is to study and solve the economic problems of port safety. It is not only a special economics, and is a specific application science which be in order to the specific application area for the management activities of port safety. The subject investigated for the economics of port safety, is the economic relations in the field of port safety, that is, the economic relations of port safety. The so-called economic relations of port safety contains the following four layers meanings: division of labor and cooperation relationship for port safety, economic interests relationship for port safety, economic quantity relationship among the various factors related to the port safety, the economic benefit relationship for port safety. These 4 aspects constitute the system of economic relationship for port safety.

The research objects for the economics of port safety, specifically, are in the operation process of the ports, according to the unity of opposites between port safety reality and economic effect, to research on how to combine port safety activities with the best way with port transportation production, to explore the best input and output ratio in production of port safety, to make the benefits maximization of port safety investments.
Specifically, it will study the following questions: (1) The macro theory for the economics of port safety, including that the influence on port safety with social development, national economic conditions and port industry development, and research on the influence of port safety which impact on the whole social economy, national security, and even the country's foreign policy. (2) Established the objective for the economics of port safety. (3) From theoretically to discuss the proportion relationship between the growth rate of port safety investments and the speed of development of port transport, to grasp and control the development direction and speed of the scale for the economy of port safety. (4) Research on the range of port safety investment. (5) To define the scope of the direct economic loss and the indirect economic loss, and to do some discussions to estimate the direct economic benefits and the indirect economic benefits. (6) On the basis of the above research, combining with the development trend port development goals, to analyze and forecast the basic trend for that adapt to port safety investment, based on fast development of the ports.

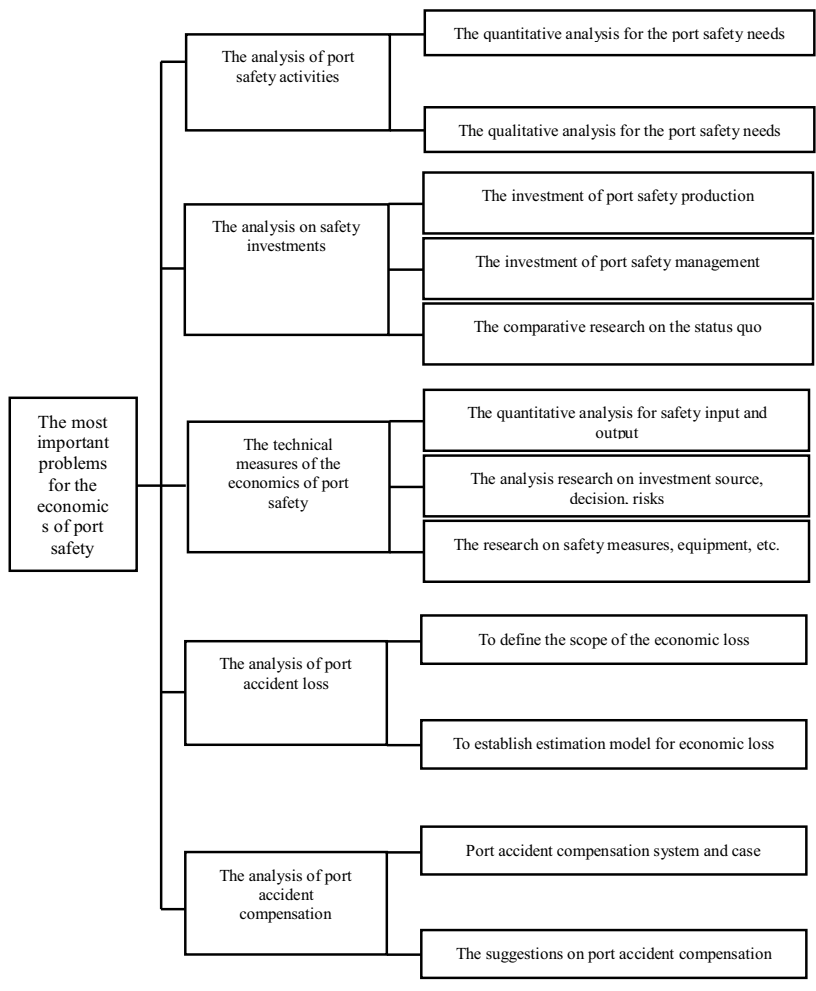

Figure 1. The most important problems for the economics of port safety.

There are many problems which worth studying in the economics of port safety. In view of the uniqueness and complexity of the economic problems for port safety, it cannot include all the contents of all. In the initial stage of research, it can choose the most important problems for the economics of port safety to analyze (Figure 1.).

First of all, it should be from the analysis of port safety activities, to the scope and type of, to illustrate the role of the safety for port transportation. On this basis, to analyze the influencing factors of port safety, to induce 
and summarize that the principle which the activities of port safety should adhere to. How to analyze the needs of the port safety? It needs to start from the two aspects of quantitative and qualitative, such as that: (1) the quantitative analysis for the port safety needs, which be including that the historical investigation of port business and safety signs, the analysis of growth trend for port traffic, and the forecasting for port safety needs; (2) the qualitative analysis for the port safety needs, which be including that the changes in the international relations, the changes of political situation and social security, the changes in the social security mechanism, etc.

The analysis on safety investments is one of the important research contents on the economics of port safety. It mainly includes the following aspects: (1) the investments of port safety production, (the types of safety production activities, the investments of the resources on human, financial and material, investment amount ratio); (2) the investments of port safety management, (the types of safety management activities, the investments of the resources on human, financial and material, investment amount ratio). (3) the comparative research on the status quo of Chinese port safety investment with foreign developed countries.

In the technical measures, based on the input and output theory of economics being applied to the research process, the related quantitative analysis is studying on the input and output of port safety. Using the investment theory and technology to the research on the analysis research for investment source, safety decision and investment risks of port safety and other issues. And being used the basic theory of economic management to study that such as the raising and management of funds for safety measures, the depreciation of safety equipment and facility, and the safety and economic management of port enterprises, and other issues.

The analysis of port accident loss is based on the necessary limits analysis and investigation of port accident and accident loss, to define the scope of the direct economic loss and the indirect economic loss, to establish the estimation model for direct economic loss and the indirect economic loss.

The analysis of port accident compensation should first introduce Chinese accident compensation system and international compensation of port accident, and to compare the different. This analysis is taking port compensation case as the analysis object, to study and put forward the suggestions on port accident compensation.

The safety benefit is the destination and goal of the research on port safety economics. The economic benefit for port safety should be including two aspects that the economic benefit for port safety and social benefit, to study on the basic content and evaluation method of the evaluation on the economic benefit for port safety, and to make prediction for the trend of port safety investments, based on the fast growing of port transportation demand. On the basis of this study, to put forward views and suggestions for the decision-making of the country's port safety.

\section{Basic characteristics}

The economics of port safety is a new special cross subject, which is being across the natural sciences and social. The subject investigated and task for the economics of port safety determine the subject characteristics (Figure 2.). From the research method for the economics of port safety, which is systemic, advance and superiority [1-4]. From the discipline essence for the economics of port safety, which is marginal and practicability.

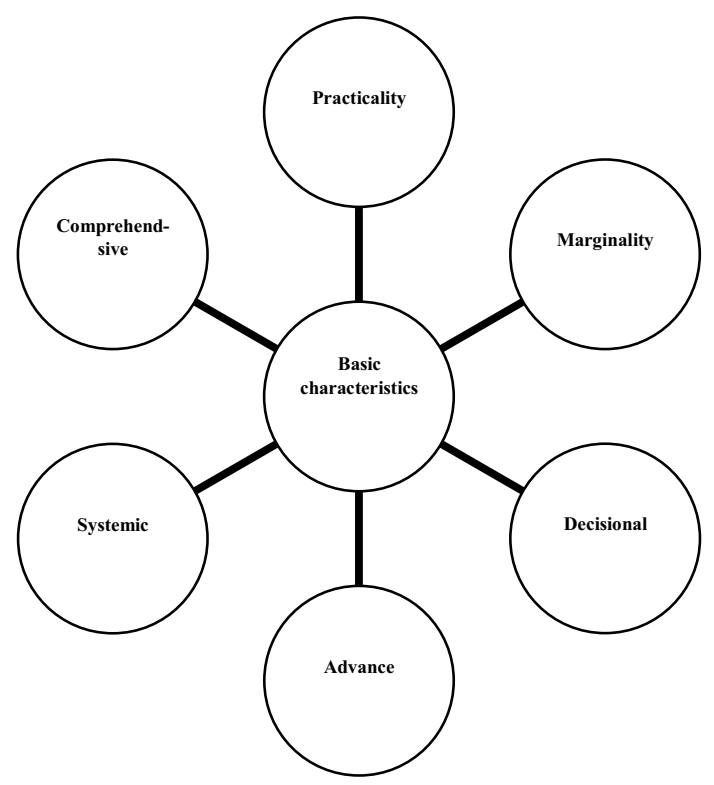

Figure 2. The basic characteristic for the economics of port safety.

(1) Comprehensive. From research content, the economics of port safety related to economics theory, and related to the basic method of safety management and safety technology, also include the basic content of port transportation. From research method, the economics of port safety is to use the basic method of economics, also make the use of safety management, safety engineering theory, but also consider the basic rules and characteristics of port. Therefore, the economics of port safety needs very strong comprehensive to carry out research, and many of the necessary factors are indispensable.

(2) Systemic. The problems for the economics of port safety are often complicated problems of multi-objective, multi variables. The safety factors and economics factors are considered in solving the problems for the economics of port safety. Also it should analyze its own factors of the subject investigated, and analyze the variety factors which associated with subject investigated. This constitutes the systematic for the research process and scope.

(3) Advance. The output for the economics of port safety is often delay and lag behind, and the essence of port safety activities has the characteristics which are foresight and preventive. Therefore, the economic activities of port safety should have to be advance which 
adapt to the requirements of economic production activities

(4) Decisional. The economics activities of port safety should be based on scientific decision-making. In the port transportation, the decision-making of safety aspects is always the priority among priorities of port management. But to ensure safety need invest. What kind of method used in the process of port safety investment is the most reasonable and guaranteed for port safety, and what way can make the maximum benefit for safety investment. So the economics of port safety will provide optimization techniques and methods for the economic decision of safety.

(5) Marginality. The economic problems of port safety like other economic problems, not only restricted by the laws of nature (the restriction of safety objective law), but also controlled by the economic laws. That is, the economics of port safety is necessary to study some natural laws of safety, also to study the economic laws for port safety. Therefore, the economics of port safety is a borderline science which is across the natural science and social science of safety.

6) Practicality. The economic problems of safety, which being researching on the economics of port safety, are all with strong technical and practical. The research on the economics of port safety is to service and protect the safety and health development of port production transportation, and port safety is as a required service in the operation of port enterprises. The economics of port safety provide the technical methods and guidance for how to ensure the safety of port transportation production, and how to achieve the rationalization, maximization, scientific for safety input and output. The economics of port safety is directly applied to the specific safety operation in port, and is really solve the practical problems of the port, which is be of great practical value.

\section{Basic method}

The basic method used in the research on the economics of port safety is the method of dialectical materialism [1, $3,8]$. The basic method should pay specifically attention to reverse thinking method, comparative analysis method, investigation and study method, and the quantitative and qualitative analysis method, also should pay attention to the combination method of macroscopic and microscopic $[9,10]$. And some scholars have also proposed the opportunity cost method. At the same time, it should absorb and apply the existing relevant disciplines, with the system method of multidisciplinary comprehensive research.

(1) Reverse thinking method. In order to achieve safety, it should be to necessary research on the condition and cause of the accident. It should start from the observation and analysis of safety accident, reversely trace the reason and condition for the occurrence of safety accident, thus to eliminate the cause and condition for the occurrence of safety accident.

(2) Comparative analysis method. Port safety system is a multi-variable, multi object system which is involving a wide range and complex contact factor.
Therefore, the research way and method should be scientific and reasonable, and should be in line with the objective requirement. The comparison analysis method is one of the basic method to grasp the characteristics and law of system. It can get accurate understanding only through analysis and comparison.

(3) Investigation and study method. In order to understand the law for the economics of port safety, it should carried out according to the existing experience and data, and to get the truth from practice. Therefore, the investigation and study method is an important method to know the rules of port safety. The rules of accident loss can be prompted and reflected only through lots of investigation and study.

(4) The quantitative and qualitative analysis method. The number relationship analysis and the scientific quantitative analysis for the economic problems of port safety, is the inevitable requirement of the development for the economics of port safety. Because of the constraint on the objective factors and the basic theory, some propositions for the economic field of port safety are not absolute quantification. It is necessary to use the method of quantitative and qualitative analysis, in order to obtain the reasonable and correct conclusion.

The concept of opportunity cost can lead into the process of research on the economics of port safety. In the real world, "no free lunch" is the true saying. Everything in the world has a price to pay. The economics of port safety also can be analyzed using the related theory of opportunity cost, in order to obtain greater benefits for input and output. In addition, it should also pay attention to set up the system and the dynamic point of view, and use the method of macro and micro.

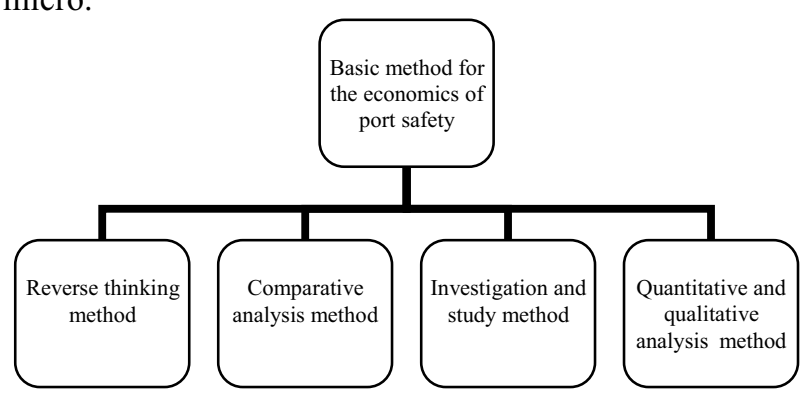

Figure 3. The basic method for the economics of port safety.

\section{Research significance}

The task for the economics of port safety is to reveal the objective law on the occurrence, development and movement for the economic relations of port safety. And the task is to discuss the realization of port safety production, safety of life, and that the way, method and measures for safety of survival. The economics of port safety not only provides the basis theoretical and reference for the scientific safety guidelines and policies formulated by country and government, but also provide technical support and basic working method for the port enterprise to organize the safety resource allocation optimization and the safety technical management. The economics of port safety can not only provide theoretical guidance for the port safety work, but also provides the 
implementation options for the actual work of port safety management. Through research on the economics of port safety, thus it can provide the maximum protection for the health and development of port transportation production, so as to promote the harmonious development of the society and economy thriving and prosperous.

To discuss the relationship between port safety and port economy, and to study economic problems of port safety, it is an important topic which constantly sought by many experts and scholars, and the actual workers. The real development of the port also continuously puts forward new requirements to the theory workers who study port problems.

Safety economics $[1-4,11,12]$ itself is in the growth stage, and the development of the discipline is imperfection. The economics of port safety as a part of the safety economics, also is imperfection, and there are very few existing research achievements. In this background, the economic significance for research on the economics of port safety is particularly important. Specifically, embodied in the following aspects:

(1) the research has great significance for port safety in production. Port safety is the basis guarantee for the development of economic benefits. There is the dialectical relationship such as correlation dependence and mutually reinforcing, between port safety and economic benefits.

(2) the research provides a theoretical basis for government decision-making in the aspect of port safety, especially to reverse the wrong understandings on port safety for some of the government departments and the port enterprises. In the port industry, it also exists the fuzzy recognition that the safety investment is not to create economic benefits, and safety investment is a completely free return. The research purpose on the economics of port safety is to make the government, corporate decision makers and safety workers who can correct understanding, on the role of safety and the benefit created by safety. So that the decision-making of port safety in the relevant departments is more scientific and practical. It must not only see the political significance, but also pay attention to the economic benefit.

(3) the research provides a theoretical tool for safety activities of port enterprises. The realization of port safety needs to invest, and the reasonable investment should be how much, how to achieve greater safety benefit and economic benefit based on limited investment. These must be the guiding theory and method of scientific selection. The related research results can be used to guide port enterprises for the reasonable selection of safety investment and safety means, in order to improve the level for the economic decision-making of safety and management.

(4) the research has practical value for establishing the system of safety management system for the throughout port industry, and for further improving the level of port safety in China. The correlation research on port safety in China is overall relatively weak. Undoubtedly, the research on the economics of port safety can greatly enrich the research content for port safety in China, and promote scientific research for port safety in China.

(5) the research has important significance to promote the study on safety economics. Safety economics is a macro research for the safety economic problems. The safety economics for port is from a field to study on the economic problems. And it is based on the related theories of safety economics to research on safety of port industry. The safety economic problems of this field can enrich the research content of safety economics from the perspective of scientific research. It has positive role in promoting the research on safety economics. In a sense, the study on the economics of port safety is groundbreaking.

\section{Conclusion}

Based on the research on the basic characteristics, basic contents and research methods for the economics of port safety, this article tries to make a little contribution in the research framework aspect for establishing the economics of port safety. The research on the economics of port safety can from different angles to study, and it is a matter of opinion. The article is from start out the general system of economics, based on the basic theory of safety economics, along the idea of the input channels, cost accounting and benefit analysis. Without a doubt, the point of view in this article is only the statements of a school, only carries on the discussion to the economics of port safety from one aspect.

The complexity of the economics of port safety put forward the challenge of milepost significance to every interested person. It needs to give more attention and research, in order to continuously expand and improve the research on the economics of port safety, for the port service, the water transport industry service and the social service.

\section{References}

1. L. Yun, Safety Economics, 2st ed. Beijing, China: Chemical Industry Press, pp. 121-123, (2010).

2. S. Dacheng, Enterprise Safety Economics, Beijing, China: Meteorological Press, (2000).

3. L. Quan, "Basic Framework and Significance on Aviation Safety Economics," Journal of Civil Aviation University of China, 27, no. 3, pp. 37-41, June 2009.

4. T. Shuicheng, Xiandai Anquan Jingji Lilun Yu Shiwu, Xuzhou, China: China University of Mining and Technology Press, (2004).

5. M. Cheng, "Port safety input and safety cost," Technological Development of Enterprise, 31, no. 17, pp. 30-31, June (2012).

6. Z. Yuhai, "The theory of enterprise's safety investment", Safety, China, no. 1, pp. 5-7, (2008).

7. W. Shengxia, Research on Enterprise Safety Investment and the System Development, Central South University, Changsha, China, May, (2011).

8. Q. Zhanyu, "Using Safety Economics in Rail Delivery Operation on the Guiding role of Safety 
Investment Decision-making," Shanghai Construction Science \& Technology, China, no. 3, pp. 64-66, (2013).

9. L. Yun, "Prospects of Safety Management Science in the 21st Century", China Safety Science Journal, 10, no. 10, pp. 27-32, February (2000).

10. Ian Savage, The Economics of Railroad Safety, Kluwer Academic Publishers, the United States, (1998).
11. L. Calvin, B. Avendaño, and R. Schwentesius, "The Economics of Food Safety: The Case of Green Onions and Hepatitis A Outbreaks," Electronic Outlook Report from the Economic Research Service, December (2004).

12. P. Dorman, "The Economics of Safety, Health, and Well-Being at Work: An Overview," May (2000). 